Received: 24.12.2013, Final Text: 24.12.2014

Keywords: Design computation; doing and thinking; hermeneutics; language; design process.

\section{A HERMENEUTICAL SKETCH OF DESIGN COMPUTATION}

\author{
Ethem GÜRER*, Mine ÖZKAR*, Gülen ÇAĞDAŞ*
}

\section{INTRODUCTION}

Computation has become a widely accepted notion in architectural design. Advances in digital technologies in the form of new devices and softwares continuously support this position. On one hand, such an inclination causes an increase in the pragmatist value of producing new techniques and products. On the other hand, it triggers new discussions in design computation concerning the basic tension between doing and thinking. This basic tension defines the core of this study.

We introduce design computation in this research as an examplary process of doing and thinking which also involves collaborative design actions. Whether the tools are digital or not, there is always a connection between acts and understandings. Schön (1992) questions the premises of AI very early on and attributes to design thinking the widely recognized phrase of "see-move-see" where move includes doing. Knight and Stiny (2001) highlight computation in a broader than usual sense and discuss the active relation between abstract representation and practical process. Özkar (2007) echoes Dewey's idea of "learning by doing" and Stiny's "spatial thinking" to reiterate the complementary relation of doing and thinking. These theoretical investigations highlight the importance of ambiguities and visual computation in design without much reference to computers. At the same time, they emphasize the variety of interpretations by a designer during a design process as well as the differentiation in different designers' interpretations. Design computation almost always deals with uncertainties coming not only from the tension between doing and thinking but also from the multiplicity of interpretation.

The ideas above find their parallel in the way contemporary hermeneutical philosophy incorporates experience and thought. Modern hermeneutics discusses the ways we evolve our understanding with the interplay of acting as a part of the world and of objectifying and influencing it. Language, in this regard, is not merely an existing system of signs, but
* Department of Architecture, İstanbul Technical University, İstanbul, TURKEY. 
serves as the mediation between the evolving understanding and static forms around us (Brown, 2002). Winograd and Flores (1986) introduce the view of language in hermeneutics by claiming that "how practice shapes our language and language in turn generates the space of possibilities for action". In this sense, language in action holds the key for not only the dissolution of the meaning of an action, but also the generation of new actions.

This study relies on the terminologies and concepts of contemporary hermeneutical philosophy, which focuses on human actions and understandings through interpretation. In addressing computational issues in design, it takes up language as the mediation of interpretation in an experimental setup with beginning architecture students.

\section{A FRAMEWORK FOR HERMENEUTICS}

Hermeneutics, known as the theory and practice of interpretation, mainly focuses on unearthing meaning. Meaning is historically situated and dependent on media and experiences through which it is observed (Brown, 2002). The root of the word relates to the Greek god "Hermes" who is known to be the intercessor between gods and mortals. Hermes brings messages from gods by translating them to people, which makes him a symbol of transition, boundary and interpretation. He makes interpretations in order to uncover meaning by bridging two different languages, contexts and worlds. Hermeneutics relies on a long history of "Biblical exegesis" developed in the first centuries AD to inform how to correctly interpret the Bible. Inquiries into the nature of interpretation only emerged in the nineteenth century through the interest of theologians in the methods and practices of interpreting ancient texts (Snodgrass and Coyne, 2006).

The contemporary philosophical approach of hermeneutics was built up with Schleiermacher's and Dilthey's studies. Schleiermacher offers a hermeneutical circle of understanding where the whole can be understood in terms of its parts and the part in terms of the whole. Broadening Schleiermacher's hermeneutics, Dilthey (1976) suggests a universal understanding that includes not only all disciplines that human engages in, but also human experience. This is accompanied with a view for hermeneutics that contradicts the dominant Cartesian understanding of the subject/object dichotomy in the nineteenth century. In this contradictory view, Dilthey emphasizes that both the subject and the object are historical and that it is impossible to understand the object without taking the subject into account. Philosophers Heidegger, Gadamer and Ricoeur engaged in the formation of a more contemporary view in the twentieth century. Through contemporary philosophy, hermeneutics became an approach for revealing meaning not only in specific disciplines or cases but also in every human experience that implies it. In developing a theoretical framework, this article calls on three pairs of notions: understanding and explanation, being-in and being-distanced, articulating and operating.

\section{Understanding and Explanation}

The first pair arises from the principal distinction in the sciences. In basic terms, human sciences aim at understanding whereas the goal of natural sciences is explanation. (Although we use the term explanation in colloquial language as making someone understand something, the philosophy of sciences takes this term as the relations of something to 
other things or to general laws). Contrary to scientific studies based on "measurable" things and facts (such as the geometry of a desk), human studies focus on incommensurable complexity, uniqueness and prejudices that humans possess. Thinkers such as Dilthey (1976), Heidegger (1987), Gadamer (1992) from within the hermeneutics tradition agree with the distinction of human and natural sciences and claim that the only way to reach meaning is understanding due to three facts (according to Klüver and Klüver (2011)) firstly humans are not identical objects, secondly humans act differently if compared to other organisms and thirdly humans usually are guided in their actions by certain world views. Explanations are generally excluded in hermeneutics.

Weber (2011) and Ricoeur (1971) contrarily argue that understanding and explanation are not against each other but rather complementary conditions of human thinking. The traditional hermeneutical circle is deficient in being grounded on just one part of interpretation, namely understanding. Ricoeur tries to challenge this deficiency by bonding understanding and explanation through interpretation since explanation constitutes an alternative way of building up interpretation as well as understanding. Understanding occurring in a subject/object unity relies on an ontological base, but there should also be a mode of explanation in interpretation that necessitates an epistemological derivation. Furthermore, the classical hermeneutical circle has a chance to become a vicious circle because of the continuous dictation of the interpreter's prejudices which can trigger a dogmatic interpretation. So, to recompose hermeneutical circularity, Ricoeur articulates the process of interpretation in a spiral model in place of Schleiermacher's hermeneutical circle (Mallery, Hurwitz and Duffy, 1986). This new hermeneutical spiral combines two complementary flows: one that moves from understanding to explanation and another that moves from explanation to understanding (Figure 1). In the first flow, understanding seems as a naïve grasping of the meaning whereas in the second flow, comprehension supported by explanatory procedures becomes a sophisticated mode of understanding. Within this move, understanding and explanation are in a neither distinct from one another nor contradictory position.

\section{Being-in and Being-distanced}

In addition to the separation of understanding and explanation, the hermeneutical spiral reconsiders another classical gap of hermeneutical philosophy between practice and work (i.e. designing and design) in a complementary manner. There emerges the second pair: being-in and being-distanced. As discussed above, Ricoeur's (1974) proposal for a new interpretation process instead of the classical hermeneutical circle combines understanding and explanation. This agrees with Dilthey's claims of both the historicity and the unity of subject and object. It also extends the classical hermeneutical circle by introducing epistemology into Heideggers's ontology based mode of understanding. Heidegger's (1987) contribution to hermeneutics can be seen as an existentialist understanding

Figure 1. Diagrammatic analyses of the hermeneutical circle and the hermeneutical spiral.

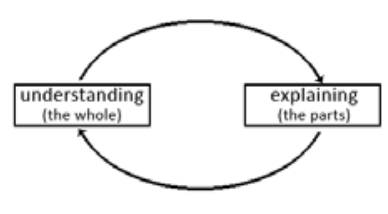

hermeneutical circle

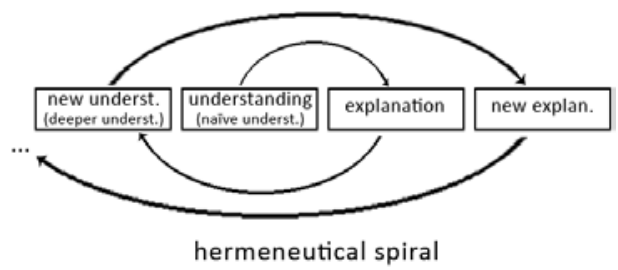


where one reaches apprehension through prejudices and perceptions. Differently, Ricoeur (1981) points out that there is also apprehension in language. This means that Dasein (being-in-the-world) is not only embedded within prejudices and perceptions but is also determined by a detachment from instant experiences through linguistic descriptions.

In these terms, interpretative tasks involve both acting and using language. Actions accommodate being-in-the-world (i.e. understanding) and words accommodate being distanced from it (i.e. explanation). This correlation provides a back-and-forth motion between being a part of the world and operating on it. The continuous interplay between thought and action triggers new meanings to be interpreted. As we think about what we might aim at, not only do we alter the way we interpret it but we also open up to new ways of seeing. The historicity of both the subject and the object comes from this instability which relies on a continuous communication that operates on both.

\section{Articulating and Operating}

Hermeneutical philosophy puts emphasis on language and the articulation of meaning through language. Heidegger (1987), Gadamer (2008), Gallagher (1992) agree with the idea that all interpretation is indeed linguistic. Language has been a crucial and central theme in hermeneutics since Ancient Greek philosophy; for example, Plato (1961) claims that Socrates, in Cratylus, recognizes Hermes as an interpreter or messenger, or thief, or liar, or bargainer that all that sort of thing has a great deal to do with language, Vine (1996) argues that according to Aristotle, hermeneutics designates how the logical structure of language conveys the nature of things in the world etc. Hence, beside the fact that language maintains a key role for communication, it is also a milieu of understanding since meanings do not exist independently of being articulated in language.

Particularly in the interpretive sense, Ricoeur's suggestion to see explanation as part of interpretation indicates a level of fixation. To put it differently, explanation, in respect to language, offers fixed descriptions of what has been realized by understanding. Such a fixation naturally triggers opportunities not only for articulating ideas, actions etc. but also for operating on them. For example, one's writings concerning one's act during an action seem retrospective for an action while differently influencing one's future actions. We can claim that writing (in action) offers both a fixation for our ways of seeing the world in an explanatory way and a network of possibilities for our future acts. Brown (2002) names this fixation as contingent by arguing that in choosing to act as if one's explanation is correct, one may face a world which resists one's actions in a slightly unexpected way, giving rise to a new understanding, resulting in a revised explanation, providing a new context for acting and so on. Thus acting accompanied with writing can both bring sophistication to a naïve understanding since writing concerns articulation of acts, ideas etc. and determine fixation levels to operate on for future acts.

The above framework can be summarized as follows:

(a) Understanding and explanation are two complementary parts of interpretive tasks.

(b) Interpretation deals with both acting and using language.

(c) Writing (in action) plays a key role for not only articulating ideas and actions in the past but also operating on those in the future. 


\section{HERMENEUTICAL VIEW OF COMPUTATION IN ARCHITECTURAL DESIGN ACTIVITY}

Computation, when considered a form of doing and reasoning rather than computer ability, is an inseparable aspect of designing. The designer does not deal with it as an independent heap of knowledge. The main point of view presented in this paper considers computation not as an isolated and external structure borrowed and used by the designer but rather as a part of the activity in practical regard which is inseparable from design acts. This consideration implies the interpretative qualities of computation in designing. It is possible to deem computation a way of doing and thinking in design once it is understood hermeneutically and as a facility that designers anyway use both explicitly and implicitly.

To understand the interpretative qualities does not mean to form a boundary between computation and design activity. Rather, since computation is not separable from designing as mentioned above, this understanding should be done in a complementary manner. To do so, this paper refers to some preliminary results of a study that focuses on uncovering the computational capability in a basic design activity with novice designers. The study aims to demystify the processes undertaken by the participants who are all first year students in the Department of Architecture at " $X$ " University. The main reason for choosing novice designers over expert designers for the study is to try to abstain from the built-in design knowledge Furthermore, it is assumed that the idea of computation is an intrinsic part of design learning for novice designers in a non-routine way and that it is important to observe how novice designers try to use computational qualities for the first time to produce meaningful compositions. In this regard, the article also presents a pedagogical study where the demystification of the analysis is guided by the main characteristics of the contemporary hermeneutics introduced above.

\section{The Framework of the Study}

The study consists of two different design exercise sets each of which includes three tasks. The duration of each task is 5 minutes. A total of 10 participants perform the exercises. Each exercise set is performed only by one half of the participants. The experimental sessions are video recorded and the participants' writings are retained.

Participants are first presented with the design elements shown in Figure

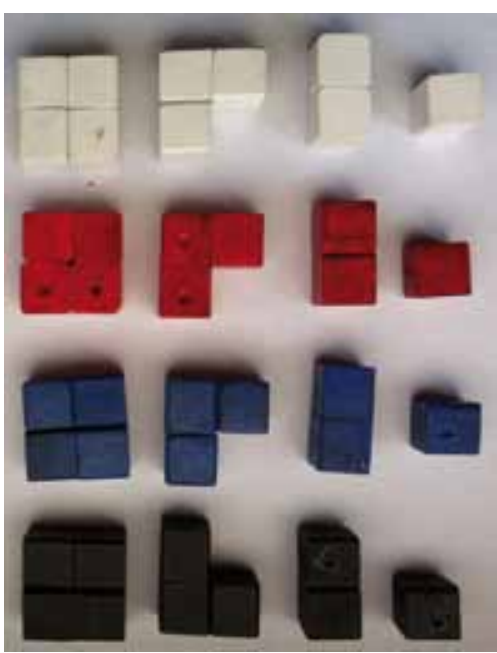
2. Three main criteria influenced the selection of these elements. Firstly, since the participants are all first year design students, the idea was to provide them easily controled geometrical forms (in a similar approach to Froebel's block selection). Secondly, there is a modular balance and hierarchy between elements. Each element is related to others in terms of proportion, modularity and size. Finally, four different colors are used both to introduce a new relational criterion additional to the geometrical similarity and to make each element unique.

Participants are asked to carry out the following tasks:

First set of design exercise for 5 participants:

1. Make a meaningful composition of design elements given to you.

2. After having completed the composition, describe your design moves or/and rules by writing. 
3. After having completed your composition, describe it within computational expressions by writing.

Second set of design exercise for other 5 participants:

1. Make a meaningful composition of design elements given to you.

2. While making the composition, describe your design moves or/and rules by writing.

3. After having completed your composition, describe it within computational expressions by writing.

The only difference between the two exercise sets is the timing of the description for design moves or/and rules in the second tasks. In the first set, participants are asked to describe their moves or/and rules after having completed their compositions whereas in the second one, the same task is postponed to the end of the design process.

Below, we introduce three discussions based on the students' performance on the tasks. Consecutively titled as (1) playing and construction, (2) acting and writing, and (3) monitoring and processing, these three conceptualizations do not correspond to the three tasks one by one. Nevertheless, the first, playing and construction, overlaps well with the first task. Differently, the second, acting and writing, and the third, monitoring and processing, overlap with tasks two and three simultaneously.

\section{Playing and Construction}

The first task of the design exercise leads the participants to produce different meaningful compositions in design processes. Both the writings and the video records show that there are mainly two sub-processes with different characteristics. We name these playing and construction. Playing has to do with the design activities conducted with a naïve understanding. Various attempts are freely carried out to determine how to act in the next phases (as in the understanding sequence of the hermeneutical spiral). Construction has to do with the bearing of specific ideas by building up design strategies and rules towards a more sophisticated understanding (as in the explanation sequence of the hermeneutical spiral). These subprocesses of design appear to be relative and complementary moments of a design process and to proceed in a continuous way while shaping each other. Yet, they also appear as the very moments where different computational characteristics of a design process also emerge (Figure 3 ).

Playing, in a general sense, constitutes the naïve understanding of design computation. It is thus seen in a variety of ways without being wrong or right. None of the participants deal with the initial attempts of the first task in an interrogative manner. The great evidence for such a claim is the participants' general complacency of giving up a particular design solution that they produce. According to video records, it is observed that 8 of 10 participants continuously change the form of their compositions, sometimes by deconstructing an important part of the composition

Figure 3. Diagrammatic analyses of the playing and construction sequences in design process.
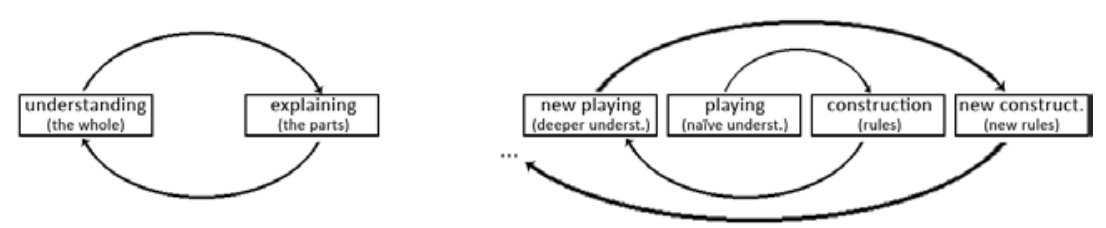
or by eliminating the whole (Figure 4). In other terms, while playing, participants do not hesitate to let the preliminary composition trials go away. Playing in a design situation has not to do with objective rules and judgments but is carried out with pre-understandings and mostly with practical rules, similar to what Snodgrass and Coyne (2006) define as the rules that "govern the conduct of societies or games, being efficacious and appropriate to the degree that they are capable of giving rise to inexhaustible possibilities of interpretation and action." The theory of playing is on this level a theory of naïve understanding as explicitly actualized in a design process. Any naïve understanding here constitutes of design compositions which may or may not be carried on for the future design moves and strategies. Moreover, it involves an initial attempt to capture meaning through the relations between the design elements.

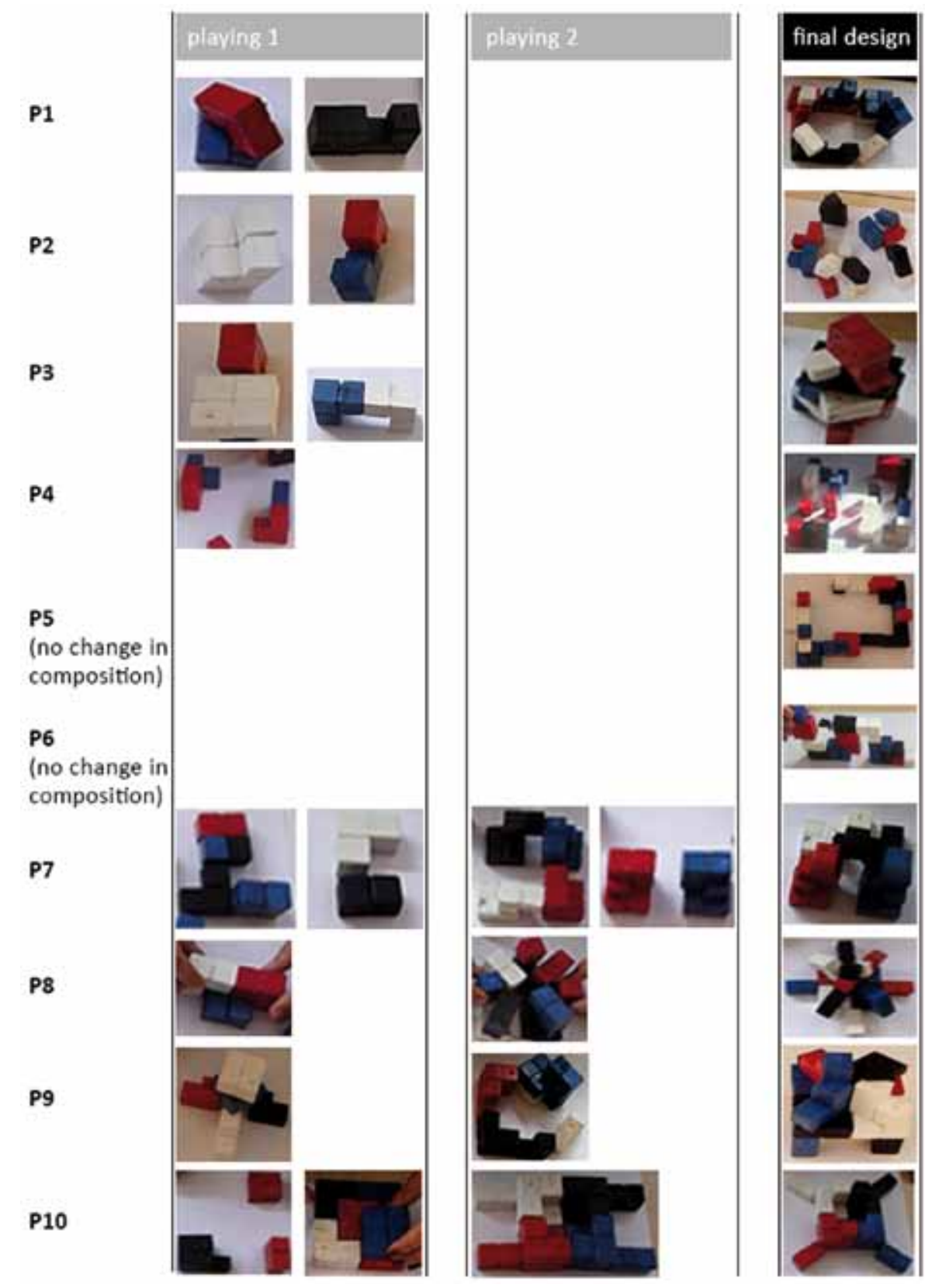


Apparently, there are plenty of ways both to form relations and to give meaning to them. Identical relations can possess different meanings whereas identical meanings can be revealed in different relations. This uncertainty is the core of the playing aspect of computation and triggers new relations to be built in a divergent sense. As a good example of the aspects of relations set between elements to reveal a meaning, consider the followings. P1 (participant 1), from the second exercise set began by trying different relations between elements. Among these trials, the spatial relation between a square element and a L-shaped element made a sense of "window" for her. In another example, P2 from the first exercise set discovered a "door" in the spatial relation of two L-shape elements. P3 of the second exercise set, similar to P2's discovery, also interpreted a "door" in a configuration of two L-shaped elements. What is common in all these relational discoveries is that they were all set up among other relational trials. Computing, in this situation, is a kind of revealing through relational compositions, all actual possibilities for proceeding in an explicit manner. Ambiguity and uncertainty are dominant characteristics.

Questions arise: at which point does this playing sequence reach to an end or more appropriately, how does this playing sequence evolve? For a playing sequence in a design process, to end up means to become a "cliché" for the designer. This is the moment where practical design rules are generally comprehended by the designer but no longer sufficient to open up new ways in their practical closed system. Hence, there is a need for escape from the physical world of explicit acts as well as from the direct references of relations through which the designer plays. Rules, as alternative to the reality of these practical concerns (not only acts but also representations such as sketches, drawings, models etc.) arises in this regard. Rules are the medium where designer carries his/her playing to a radical questioning. Remember the previous 3 examples given: students discover not only a specific visual relation from which they can reveal a meaning but also a particular rule that creates this particular relation between design elements and through which they can operate on in the future. The function of the rules in design process thus includes not only a translation of an expression or an idea into another one in a 'comparable quality' but also a new makeup. In a hermeneutical sense, building up rules in design is the moment where the flow from understanding to explanation through playing sequences evolves to a secondary one: construction.

Construction begins within the subjective character of revealing meaning through relations and goes on within the objective character of validating this hypothetical assumption by generating own design strategy. What designers tend to construct is the validation of a meaning uncovered by the relational aspects in a naive playing sequence. Noticeably, there exist many computatinal forms of such an act such as repetition, variation, hierarchy, rhythm etc. that relate to local quantitative and qualitative differentiations in global similarities. P1, as the first exemplar, after having noticed the relation between the square element and the L-shaped element, named it as "window". Meanwhile, she also noticed a rule for "window". This was the moment where she left playing and began to construct. The rule helped her proceed. She then tried to validate this hypothetical rule by producing repetitions of it with different element pairs (Figure 5). P4, from the first exercise set, produced various relations between design elements. He ended the playing sequence by making sense of a combination of a square element and a L-shaped element as a corner for a space. This was a constructionist approach rather than a functionalist one. He kept the 
Figure 5. Participants' different construction methods.

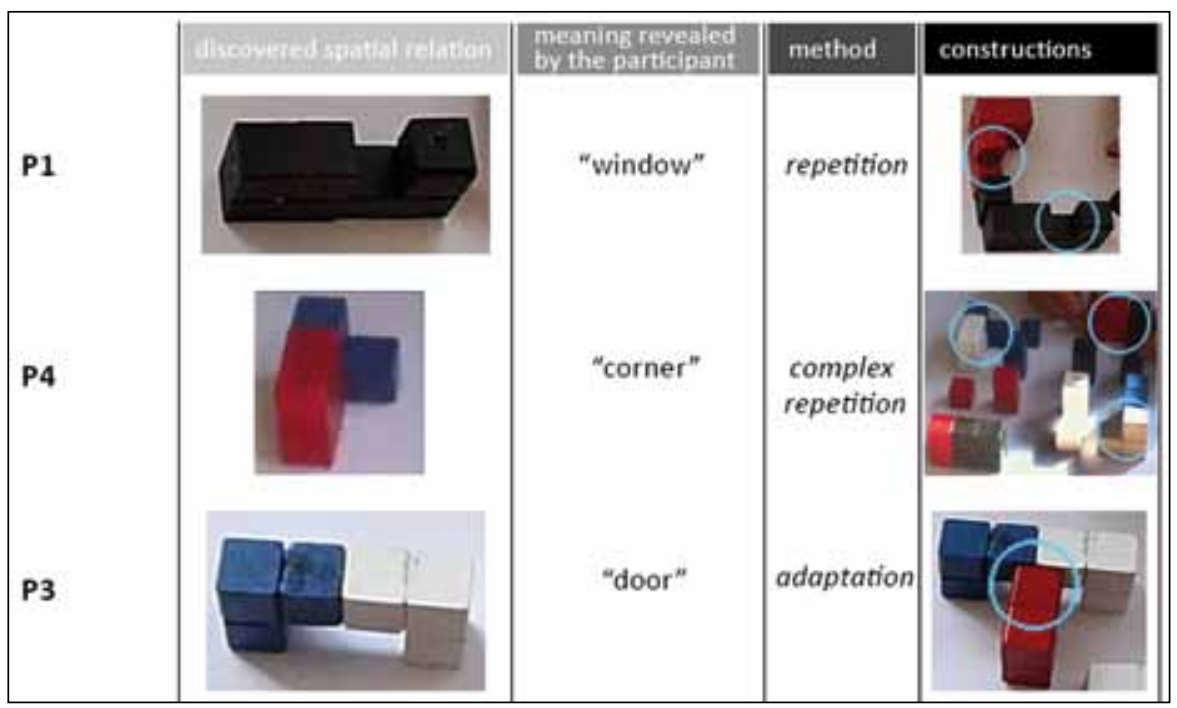

Figure 6. Duration and order of the sequences of participants' playing, construction and writing.

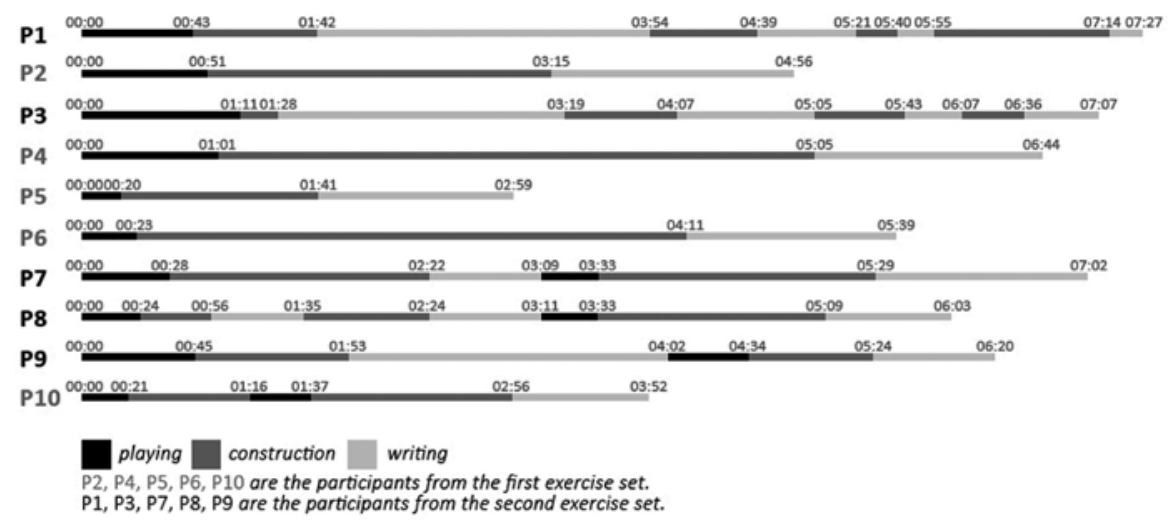

rule forming this relation and he then applied it in a complex repetition to determine the borders of a composition (Figure 5). P3 chose a different way of validation; she neither made a repetition nor a rhythm of her basic configuration. Rather, she made an adaptation of the rule by combining three identical elements of different colors (Figure 5).

Construction in computation consists of different rule-based possibilities that ground in reasoning. Whatever these possibilities are, the common point in construction is the validation of a "meaningful" relation through a more generalized rule. This does not mean that a design process goes on accompanied with the reasoning of a single rule. Plenty of rules exist in a process. That is why computation is like a hermeneutical spiral which always happens in playing sequences that motivate new constructions that cause new playings again and again (Figure 6).

\section{Acting and Writing}

Computation in design, as mentioned above, involves both the subjective character of understanding in playing to be able to comprehend what a design situation can talk about, and the objective character of explanation in construction to be able to comprehend what a design situation can consist. This continuous back and forth movement proceeds in a repetitive way between playing within the whole design and constructing within the parts of it. Designers are capable of acting through both of them and the 
common point within these two features of computation is the practical character. Both playing-in-action and construction-in-action necessitate a practical engagement and on one hand, computation by acting is very crucial since it develops a practical reasoning for designers.

On the other hand, generally, designers are not aware of computing while designing. Even though they discover relations, frame these relations by rules and apply these rules with variations, all of these generally proceed in an implicit way. This is the point where doing computing in design (beingin) needs a complement in a different view (being-distanced). The structure of the studies, in this regard, is based on experiencing design computation both within acting and writing. Acting has to do with a continuous practical evolution of being-in-design (as in the being-in mode of hermeneutics). Writing has to do with a linguistic exposition, objectification and more particularly fixation of design acts, ideas, strategies etc. (as in the being-distanced mode of hermeneutics). Brown (2002) suggests that through this sort of fixation in writing, we can use interpretative techniques in facilitating both understanding and explanation. Writing thus constitutes an important moment of critical regard within the process of interpretation which means in design terms that situation in which designer acts change in a continuous manner but the meaning of these can be framed and interpreted in a fixed manner.

The main purpose is to invite participants to explore dimensions of their actions beyond the limitations of a specific design situation in order to show their sort of designing unfolded within their design itself. Writing plays a key role here as a medium to describe and to organize the acts for the future. While discussing the relation between design acts and computation, a critical question arises: How does an action become an object of computation? Ricoeur (1981) argues that the meaningful effect of an action is its objectification through description. Therefore, writing is important because of the gap between subjective intentions of the designer and the objective significance of how/what she designs. At this juncture, for a design action, becoming an object of computation relates to its objectification through writing. Writing provides the dissolution of the meaning of a design action from the event itself; once the issue shifts from a designer's voluntary act to a linguistic articulation of it in writing, questioning begins. Our expectation in encouraging students for exposing themselves by creating their own worlds through writing, is for them to shift the emphasis from the idea that computation only deals with algorithms that focus on the continuity of relations between situations, to the idea that computation also concerns escapes from concrete descriptions of design situations towards new worlds of seeing. Particularly in this study, texts written by the students in natural language while/after designing constitute an intermediary pedagogical step towards computational design thinking rather than a result of computer readable language for automation.

At this juncture, writing is used as a medium for supporting participants to develop a critical distantiation to their design both as a process like in the $2^{\text {nd }}$ tasks and as a product like in the $3^{\text {rd }}$ tasks. By asking for two types of distantiations, students are expected to consider computational thinking in a complementary unity of process and product. For a comparison, we treat the inferences obtained from the writings of describing both designing (process) and design (product) in three categories: abstraction, coherence and uncertainty. 
Abstractions: functional and definitional

Tversky (2005) points out the importance of making different connections in design, between features of objects, events and places through different levels of abstraction. That is to say that some features can call up properties of appearance whereas some can call up functional properties and what make for a productive level of thought are these connections between form and function. In this regard, it is observed that writings for describing the design process generally include functional abstractions whereas writings for describing the final composition generally include definitional abstractions. For instance, consider the following passages written by the participants P2, P5 and P6:

For the $2^{\text {nd }}$ task:

P2: “...I began with making a door...I used blue cubes to form a wall...I wanted to construct a roof and a roof window by placing two L-shaped elements one on the top of the other..."

P5: “I wanted to make a conference hall. Firstly, I intended to form the stage by placing the white rectangular prism between two red and blue small prisms...I thought to use a regular form for audiences."

P6: "I saw different relations forming a stair...Then I found out that I can generate different partial stair compositions in one whole..."

For the $3^{\text {rd }}$ task:

P2: "There are 8 cubes at the door, 12 at right, 5 at left, 1 at the center, 6 at the back and 10 at left back."

P5: “The composition begins with a vertical $2 \times 1$ form and goes on with a horizontal placement of the same dimensions...1x1, 2x1 and $2 \times 1$ forms are consecutively placed..."

P6: "1 unit, 1 unit, 2 units, 3 units, 5 units, 1 unit, 2 units, 4 units and units from the front view. Different descriptions are possible."

Coherence: the relation between the description and what is described

Students seemed able to describe how they produced more precisely. Nevertheless their descriptions concerning the final stage of composition were less coherent to what they produced. This is despite the fact that the latter seemed to include more detailed information. Possible reasons for this are that students are either more used to describing actions rather than static situations or they discover new visual relations while reconsidering the whole composition. The first reason correlates with the idea that teaching and learning computation should be more focused on the interpretation of the design situations as well as on the interpretation of the design actions. The second correlates with the ambiguities and uncertainties which emanate from a part/whole dialectic.

Uncertainty: part/whole relations in changing interpretations

The most crucial difference between the two types of writing tasks is in the participants' descriptions for the same situation. Besides the fact that they often use different levels of abstraction to explain the process and the product, they also use different descriptions even in a specific abstraction level which indeed triggers the ambiguous quality of computing. The importance of ambiguity in design computing is highlighted by Stiny (2006), Knight (2002) and Özkar (2007) who relate the visual uncertainties 
to creativity in computation. Here, we pay attention to underline such uncertainties in a more "certain" way of exteriorization like writing since writing offers first a fixation in time as already discussed and second a medium to discuss meaning through changing interpretations.

The key point between writings for second and third tasks offered for the same situation can be seen in a part/whole dialectic. In these examples, participants tend to describe their actions in an independent manner where every element or relation used in these actions and the meanings of them are separately explained: one meaning for elements or relations used in an action. This is also the reason for framing this kind of describing more coherent but less ambiguous. Contrarily, while describing the final designs, we discover that participants tend to form relations between independent parts and this obviously changes the meaning of a situation as well as the interpretation of it that all bring about uncertainties. To exclude the procedural descriptions triggers new relations to be formed between elements towards an understanding of the whole. So these two types of writings form a part/whole dialectic in different manners: the first one focusing on "how is it?" moves from a unitary understanding towards an elucidation of the parts and the second one focusing on "what is it?" moves from the parts towards a total composition.

The outcomes of computational design activity are in terms of computing as acting, and computing as making sense of the experience through writings about the process and the product. This ongoing negotiation between computing as acting and computing as writing can be seen as a complementary way of revealing two different computing qualities: one which focuses on the meaning shaped through acts and events, one which focuses on the meaning shaped through elements and compositions. Moreover, trying to enrich the distanced character of writing by generating different focuses (like process-oriented and product-oriented) displays firstly different abstraction levels that support productivity, secondly a medium to scan the coherence degree between what has been done and how it is described and thirdly a part/whole dialectic through the uncertainty of the changing interpretations.

\section{Monitoring and Processing}

The more we drive design acts and words together, the more we benefit from changing motives and perspectives of language in design computing. Process-oriented descriptions and product-oriented descriptions offer complementary ways for understanding computation. Each of these descriptions refers to different qualities of computing such as the disclosure of the evolutionary relations between acts and the exploration of meanings through elemental and spatial relations. Yet, they both possess only one character of language use: articulating. Since they both refer to past events or to actual existences, they do not offer a possibility for the future ones. Nevertheless, in addition to the monitoring role of language in writing, we should also consider its processing character which supports our operational acts as a part of the design being described. Therefore, the efforts to capture computing in writing can also be considered as a medium to operate on it. In this regard, the study considers two roles for writing in computing: monitoring and processing. Monitoring has to do with the articulations of the conditions in which we acted in the past and the situations in which we mean relations (as in the articulating notion of hermeneutics). Processing has to do with the operational creation of the 
conditions and the actions through which we can produce new variations of relations to mean (as in the operating notion of hermeneutics).

In order to capture these qualities of computation in writing, design exercises are differentiated from one to other by changing the second tasks. In the second task of the first exercise set, participants are expected to shape their descriptions after having shaped their design process whereas in the second task of the second exercise set, they are expected to shape them together. The essential purpose is to capture the effects of driving design acts and words together as computational qualities in the senses of monitoring and processing. The following examples from students' writings are introduced in order to show these qualities.

P7, from the second exercise set, tried to conduct his design moves with a description of 5 steps:

"1. I separated the elements in 4 different colors.

2. I placed separately the square elements on the ground.

3. I gave altitude with the L-shaped elements.

4. I built towers with the small elements left.

5. I built a closed garden with 4 entrances."

The most interesting point in this case is the timing of the participant's writing these 5 steps and in the way he articulates his actions in writing (Figure 7). Relating to the first point, he first wrote the first 2 steps after having separated the elements and placed some of them as he described. Then, he turned back to acting and continued to design until the end. At the end, he completed his description by adding the other 3 steps. So what was the reason for him to describe in two particular times? In the first step, we see that P7 not only explained what he had done but also offered a general rule for the whole design process, which was grouping elements by color. In the next step, related to the first one, he offered the application of this rule for placing square elements. After having described these two steps, he almost appropriated his actions and came to understand his design strategy. He used writing both for describing what he had done and for continuing to process the rule that he can use in the future. Thus, he never turned back to writing until the end of the process. The subsequent 2 steps were all related to this appropriation. What he wrote for the fifth step was already in his mind since he completed the first two ones: "...a garden with 4 entrances".

The second point is the effect of articulating an action in language to

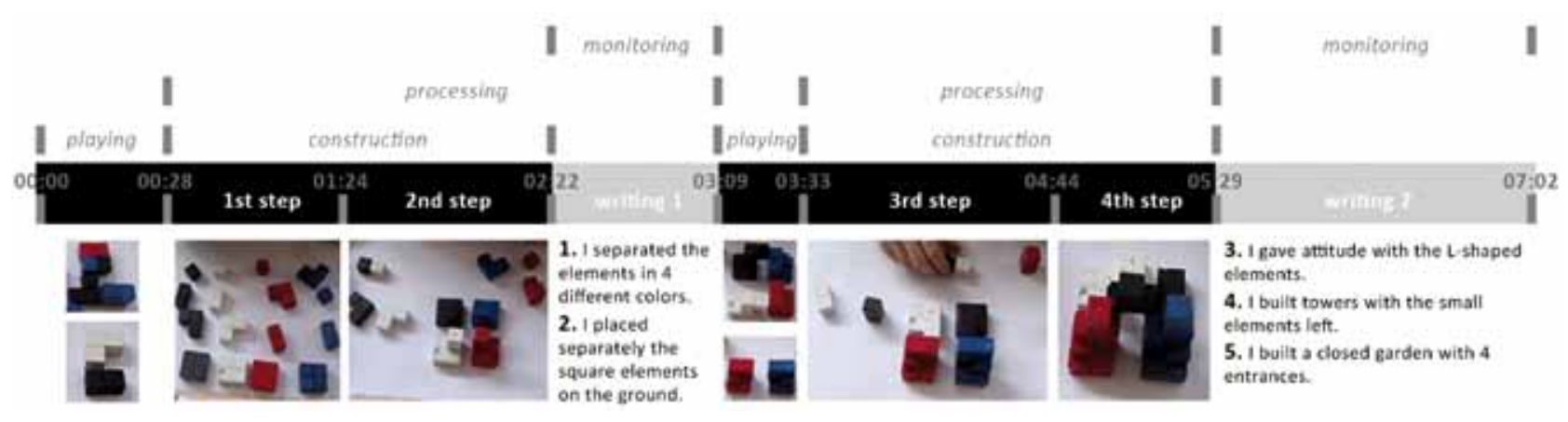


his action as "separating". Directly in the next step of writing and in the practical rest of the exercise, he used this definition and he always tried to make a separation between elements of different color. A similar example can be observed in the third step of the description. He defined his action as "giving altitude" which was later associated to "building towers" in the fourth step of the description. So, writings here reflect on the future actions as well as on the future meanings.

In another example, P8, one of the students who participated in the second triplet of exercise, made a description of 6 steps for describing her moves:

"1. I formed a big square with the small ones.

2. I added the L-shaped elements on the corners of it.

3. I put the rectangle elements on the midpoints of the big square.

4. I formed a bigger rectangle with small elements.

5. I rolled the L-shaped elements and the rectangle elements.

6. I put the small elements between the L-shaped elements."

The process P8 used for doing the exercise is quite similar to P7's one. She started with a playing sequence where she searched for meaning in various elemental relations. She found meaningful to use the same geometrical elements of different colors in mutual compositions. The processing began with this rule discovery and proceeded within writings where she externalized the conditions (a big square of small ones, L-shaped elements on the corners) for this rule. Finally, she monitored the process. Unlike P7, she completed her writings in 3 steps which were all, once again, extensions of the constructions sequences (Figure 8). In the first writing, she mentioned that she had formed a big square with the small ones which can be interpreted as she pointed a part/whole relation. In the second writing, she wrote that she had formed this time a bigger rectangle with the small elements. There is a similar connection between other descriptions too. For instance in the first writing, she wrote that she had added the L-shaped elements on the corners of the "big square". Again in the second and in the third writings, she related to this particular interpretation of action that signifies an addition of new small design elements to the actual big one (part/whole relation) as "I put the rectangle elements on the midpoints of the big square" and "I put the small elements between the L-shaped elements". This means that the articulation of design acts by writing shifted to a general operation strategy for the whole design process as it had happened in the same manner in P7's protocol.

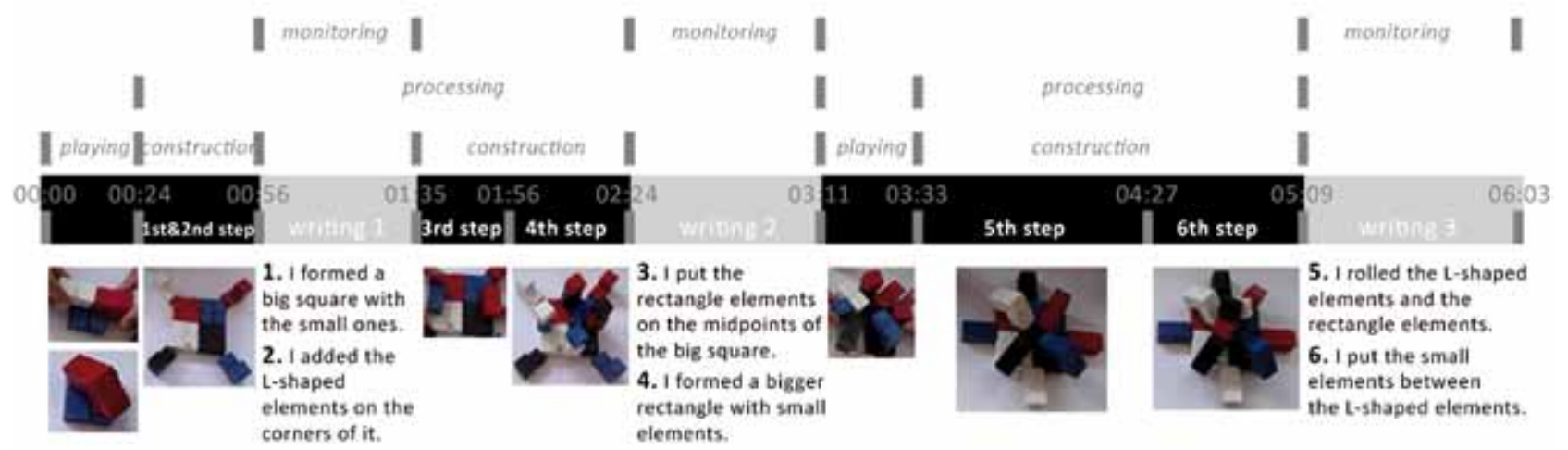




\section{Discussion on the Implications of Acts and Words}

The empirical findings briefly sketched above imply the points below with regards to, considering acts and words together in a design process:

- The more design actions are externalized by writing (and inevitably by reading), the more meanings are uncovered in writings and carried to future actions and writings. While objectifying design actions and situations in writing, paths to follow become more evident. Computation does not only involve bringing a design situation or action in a rule-based form. It also involves interpreting something as an eventuality.

- Instant transformation of the visual relations to the linguistic domain opens up new horizons for future design moves. Vocabularies used to describe both the actions and the relations trigger the invention of new vocabularies and in turn the creation of new domains for future actions. Interpretations are neither fixed nor arbitrary. Thus, this shifts the idea of computation from an inability of suggesting anything more intelligent than descriptions or actions in a closed system, to the ability of benefiting from the changing motives of using language.

- The monitoring character of writing has to do with the objectification of design situations and actions, whereas processing has to do with the creation of ways to influence and to orient design actions. By integrating writing activities to the design process (writing in action), writing becomes part of the things being monitored and processed, and provides a medium for reconfiguring the design situations for future moves. Here computation is emphasized as an act that augments designer activities and thinking rather than automating them.

- On one hand, such a verbalization through writing in the studies offered a powerful access both for the student to compose his/ her ideas about a design situation in an explicit way and for the researcher to avoid possible overinterpretations about students' thought processes. On the other hand, since such a reflective intervention changes the natural resonance of the design process by adding a "writing sequence", it carries a risk of giving a common data because of the degree to which architectural design students (novice designers) reflect their motivations through verbalization. It is thus assumed that obtained findings and results accordingly characterize a pedagogical standing for novice designer activities.

\section{CONCLUSIONS}

In this paper, the main characteristics of hermeneutics are related to design computation through a protocol analysis of sample design tasks. Interpretative aspects of design computation are reconsidered in theoretical and practical senses. As in the metaphor of hermeneutical spiral, computation is assumed to begin where prejudices (such as initial perspectives, design languages) meet an explicit situation to lead to the discovery of unannounced, unexpected playing results. It is observed in the exercises that this new situation obviously requires a new understanding that can be reached through the revision of the initial one or the creation of a new one. In both cases, the common point is that these unexpected results 
require validation in a construction. Specifically in computational design, such a validation often relates to produce either a general rule or a strategy that can be applied in similar design situations or variations of it. The new understanding then emerges as the new initial point for the next spiral of computation process. Thus computation might be seen as a collocation of discovering spatial relations through some divergent playing in a context and of validating the usability of these discoveries through design rules and strategies produced in a convergent construction.

Although the fact that practical reasoning is crucial in design computation (as in playing and construction), especially novice designers are generally not aware of it. Acting at this juncture requires a distantiation. In this study, such a distantiation has been supported in writing descriptions about the process and the product. The differentiation between describing a process and a product has been discussed in three levels: abstraction, coherence and uncertainty. It is observed that more descriptions are based on the design process; the more descriptions contain functional abstractions instead of descriptive ones, the more they are coherent with the described and the less ambiguous due to the fact that they often ground on partial explanations of the whole.

Moreover, writing has been introduced here firstly to support such a distantiation in linguistic interpretations through monitoring design acts and design compositions at different moments of the process and secondly, to produce new understandings for the future acts through processing how/what has been revealed. Particularly, writing was taken as a medium where design experiences (doing) and design thoughts (thinking), contextual details on a design problem and general inferences from local descriptions bridge together in the universality of the word. Participants' different timing for when to describe design moves/rules in the process has been analyzed and revealed that they particularly follow the construction sequences rather than the acts being described. This conforms well to the idea that processing in computation can be grounded on the dialogue between construction sequences and writing. On the negative side, no direct relation between playing sequences and writing has been noticed. The diversity and the richness in playing moves were not well exteriorized in descriptions even though they happened in actions. Anyhow, the pursuit of this relation likely needs to be questioned in a further study as it may shed light on the problem of the difficulty of capturing tacit knowledge and uncertainties.

The importance of discussing design computation through interpretation comes from the idea that a designer is expected to deal with a design situation in his/her world and words. Although studies on computation in design often relate to determined knowledge packages that neglect the very relations between doing and thinking in design process, hermeneutical philosophy which grounds on interpreting, is useful in bridging this gap. This study accentuates writing as an instant demonstration of objectification with the aim to demystify the acts of articulating (monitoring) and operating (processing) in computational design.

\section{ACKNOWLEDGEMENT}

The authors would like to acknowledge the anonymous group of students who participated in design exercises and the assistants who helped in the experiment. 


\section{REFERENCES}

BROWN, T. (2002) Mathematics Education and Language: Interpreting Hermeneutics and Post-Structuralism, Kluwer Academic Publishers, Dordrecht.

DILTHEY, W. (1976) The Development of Hermeneutics, Selected Writings, ed. H.P. Rickman, Cambridge University Press, Cambridge.

GADAMER, H.G. (2000) Towards a Phenomenology of Ritual and Language, Language and Linguisticality in Gadamer's Hermeneutics, ed. L. K. Schmidt, Lexington Books, Maryland; 19-50.

GADAMER, H.G. (1960) Wahrheit und Methode, Hakikat ve Yöntem, trans. H. Arslan, İ. Yavuzcan (2008) Paradigma Yayınları, İstanbul.

GALLAGHER, S. (1992) Hermeneutics and Education, State University of New York Press, New York.

HEIDEGGER, M. (1953) Sein und Zeit, Being and Time, trans. J. Stambaugh (1996) State University of New York Press, New York.

HUSSERL, E. (1954) Die Krisis der europaischen Wissenschaften und die transzendentale Phanomenologie, The Crisis of European Sciences and Transcendental Phenomenology, trans. D. Cart (1970), Northwestern University Press, Illinois.

KLÜVER, J., KLÜVER, C. (2011) Social Understanding: On Hermeneutics, Geometrical Models and Artificial Intelligence, Springer, New York.

KNIGHT, T., STINY, G., (2001) Classical and Non-classical Computation, arq: Architectural Research Quarterly (5) 355-72.

KNIGHT, T. (2002) Computing With Ambiguity, Environment and Planning B: Planning and Design 30(2) 165-80.

MALLERY, J.C., HURWITZ, R., DUFFY, G. (1986) Hermeneutics: From Textual Explanation to Computer Understanding?, Memo no: 871, MIT AI Laboratory, Massachusetts.

OZKAR, M. (2007) Learning by Doing in the Age of Design Computation, Computer Aided Architectural Design Futures 2007, Proceedings of the 12th International CAADFutures Conference (11-13 July 2007) eds.

A. Ong, A.V. Moere, J.S. Gero, Springer, Dordrecht; 99-112.

PLATO (1961) The Collected Dialogues including the letters, in Cratylus, trans. B. Jowett, eds. E. Hamilton, H. Cairns, Princeton University Press, Princeton, 460-74.

RICOEUR, P. (1971) The Model of the Text: Meaningful Action Considered as Text, Social Research: An International Quarterly of the Social Sciences (38) 529-55.

RICOEUR, P. (1974) Le conflict des interprétations: Essais d'herméneutique, The conflict of interpretations, ed. Don Ihde, trans. W. Domingo, R. Sweeney, P. McCormick et al, Northwestern University Press, Evanston, Illinois.

RICOEUR, P. (1976) Interpretation Theory: Discourse and the Surplus of Meaning, Texas Christian University Press, Fort Worth.

RICOEUR, P. (1981) Paul Ricoeur Hermeneutics and the Human Sciences, ed. and trans. J.B. Thompson, Cambridge University Press, New York. 
SCHÖN, D. A. (1992) Designing as Reflective Conversation with the Materials of a Design Situation, Knowledge-Based Systems, 5 (3) 3-14.

SNODGRASS, A., COYNE, R. (2006) Interpretation in Architecture: Design as a way of thinking, Routledge: Taylor \& Francis, New York.

STINY, G. (2006) Shape: Talking About Seeing and Doing, MIT Press, Cambridge, MA.

TVERSKY, B. (2005) On Exploring Parts and Wholes, Computational and Cognitive Models of Creative Design VI, Key Centre of Design Computing and Cognition, eds. J.S. Gero, M.L. Maher, University of Sydney, Australia; 3-16.

VINE, W. E. (1996) Vine's Complete Expository Dictionary of Old and New Testament Words, ed. Thomas Nelson, AMG Publishers, Tenesee.

WEBER, M. (2011) Methodology of Social Sciences, eds. and trans. E.A. Shils, H.A. Finch, Transaction Publishers, New Brunswick, New Jersey.

WINOGRAD, T., FLORES, F. (1986) Understanding Computers and Cognition: A New Foundation for Design, Addison-Wesley Publishing Company Inc., Menlo Park California.

Alınd1: 24.12.2013, Son Metin: 24.12.2014

Anahtar Sözcükler: Sayısal tasarım; yapma ve düşünme; hermenötik; dil; tasarım süreci.

\section{SAYISAL TASARIMIN HERMENÖTIKK BİR TASLAĞI}

Günümüzde sayısal tasarım düşüncesi, mimari tasarımda önemli bir kabul görmektedir. Yeni tasarım araç ve ortamlarının üretimini destekleyen sayısal teknoloji alanındaki gelişmeler, bu kabulü desteklemektedir. Bu durum, bir yandan yeni tasarım araç, yöntem ve ürünlerinin geliştirilmesinde önemli bir artış sağlarken, diğer yandan, sayısal tasarımda yapma ve düşünme kavramları arasındaki ilişki üzerinden yeni tartışmaları da beraberinde getirmektedir. Yapma ve düşünme arasındaki temel ilişki, bu çalışmanın ana odağını oluşturmaktadır.

Sayısal tasarım bu çalışmada, hermenötik bir yaklaşım içerisinde, bir yapma ve düşünme etkinliği olarak tanımlanmaktadır. Tasarım etkinliği içinde bir akıl yürütme süreci düşüncesinin, sayısal tasarım tartışmalarına önemli bir bakış açısı kazandıracağı düşünülmekte ve bu bağlamda, sayısal tasarımın yorumlayıcı özellikleri "hermenötik" düşüncenin kavram ve süreçleri aracılığıyla tartışılmaktadır. Tartışmaya yön veren noktalar, 1 . sınıf mimarlık öğrencileri ile yürütülen bir temel tasarım çalışmasının süreç ve ürünleri üzerinden örneklenmektedir. Katılımcıların tanımlı bir tasarım probleminde sayısal kurgular üzerinden ürettikleri anlamlandırmalar, yorumlamanın anahtar kavramları ile ilişkilendirilmiştir. Yorumlama, eylem ve düşünce arasındaki farklılıkların dil içinde ifşasına dayanmaktadır. "Hermenötik" düşünce ise dile, yapısal noktalardan çok, düşünce ve eylem ile olan etkileşim noktalarından vurgu yapmaktadır. $\mathrm{Bu}$ anlamda çalışma, eylem eşliğinde yazmanın gerek tasarımda sayısal düşünce ve eylemlerin ifadelendirilmesi ve izlenmesi süreçlerinde, gerekse de gelecek eylem ve düşüncelerin kurgulanması ve işlenmesi süreçlerindeki faydaları üzerine eğilmektedir. 
ETHEM GÜRER; B.Arch, MSc., Ph.D.

Graduated as architect from İstanbul Technical University, $\mathrm{PhD}$ in the Architectural Design Computing Program. egurer@itu.edu.tr

MİNE ÖZKAR; B.Arch, M.Arch, Ph.D.

Trained as an architect at METU, holds an SMArchS in design inquiry and a PhD in design and computation from Massachusetts Institute of Technology. After employment at METU (2004-2011) and adjunct status at İÜ (2009-2011), is currently an associate professor at İstanbul Technical University where she teaches computational theory and design in architecture.ozkar@itu.edu.tr

GÜLEN ÇAĞDAŞ; B.Arch, MSc, Ph.D.

A graduate of İstanbul Technical University, Faculty of Architecture, has taught at the same institute since 1981. A professor since 1997. She is currently head of the Department of Informatics, coordinator of the graduate program in Architectural Design Computing. cagdas@itu.edu.tr 